\title{
A Field Exploration of Informal Workplace Communication
}

\author{
Bruce Fortado \\ Department of Management, University of North Florida, Jacksonville, USA. \\ Email: bfortado@unf.edu

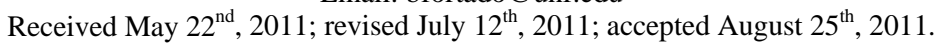

\begin{abstract}
Two views of informal communication are developed for purposes of comparison. Multiple incidents from two US companies are described based on fieldwork. In both cases, managerial efforts were made to quell gossip. Paradoxically, the versions multiplied at the first site and a gossip spiral occurred at the second. Our inductive analysis reveals the shortcomings of the existing "best practices" and simple theories. Notably, in both cases certain aspects of informal employee organization were more functional than some of the formal practices were. Due to the complex nature of these social situations, great care must be taken in evaluating them and charting a course.
\end{abstract}

Keywords: Grapevine; Informal Communication; Informal Organization; Rumor; Resistance

\section{Introduction}

In the 1930s, it became generally known that in addition to studying the highly visible aspects of formal work organizations, much could be learned from developing the less visible informal aspects of human organization (Barnard, 1938; Roethlisberger \& Dickson, 1939). Numerous field studies dealing with various aspects of informal organization were carried out over the course of the subsequent decades (Dalton, 1959; Roy, 1960; Gabriel, 1995, 2000; Knights \& McCabe, 2003). Informal workplace communications will be the central focus of this paper. Gossip is sometimes defined as being value laden statements about people, rumors as being statements about things, and the grapevine as being all forms of informal communication (Noon \& Delbridge, 1993).

Some managers and consultants view gossip, rumors and the rest of the grapevine as destructive cultural antimatter. Accordingly, measures are often endorsed to lessen if not eliminate these potential dangers. Other people view all of these varied forms of informal communication as natural cultural matter. Both good and bad results may arise. Instead of making a sweeping universal judgment, one could alternatively make limited situational judgments. The potential for productive and destructive informal activity can be thought of as being like the interlocking black and white swirls of the yin and the yang (Morgan, 1986). Under this view, managers should take care not to make matters worse instead of better when they try to exert greater control. This paper will explore these issues based on two case studies from the USA.

\section{Two Views: Cultural Matter or Antimatter?}

Viewing workplace gossip, rumors and the rest of the grapevine as destructive cultural antimatter has a long heritage. In the early portion of the $20^{\text {th }}$ century, no talking rules were sometimes enacted. Management paid employees to work, not socialize. Windows were sometimes bricked up to reduce potential distractions. This "efficiency mentality" was often combined with Scientific Management methods. Supervisors verbally pushed workers to produce under what was termed the “drive system" (Jacoby, 1985). Over time, increasing mechaniczation and bureaucracy lessened the need to "drive" people. "Paternalistic" family rhetoric and practices were often used.

The reliance on formal rules continues to date, but the nature of them has evolved. In modern times, we have seen rules instituted against talking about appraisal ratings, raises or base salary levels. Sexually oriented speech and printed materials have been banned. Various no fraternization rules were created to reduce perceptions of favoritism and divisive gossip. Ethics programs utilizing anonymous reporting have been adopted to cut short any wrongdoing. Practical advice has been generated on how to handle specific outbreaks of gossip or rumors. Managers, for instance, have been told the "best practice" is to adopt open and participatory communication practices, issue denials from credible sources and instruct people to desist (Bordia, et al., 2006: p. 617).

As the popularity of Scientific Management waned, new efficiency programs emerged. In the past 30 years, total quality management, reengineering, Kaizen, Six Sigma, and lean manufacturing have all experienced some popularity. Paternalism has continued to be relied upon (Fleming, 2005). Cultural materials were frequently introduced to capture the employees' hearts and minds. Managers in various organizations have introduced changes with titles such as "a team culture," "a customer service culture" and "a sales culture." In some of these situations, reliance on formal controls has been lessened in favor of self control and peer discipline (Barker, 1999).

Unwritten managerial norms on how subordinates should act also exist (Jackall, 1988). A wide variety of managerial silencing behaviors have been documented via fieldwork. These include chewing subordinates out (Moch \& Huff, 1983), condemning them for being prideful or arrogant (O’Day, 1974), making an example of one of them (Fortado, 1994), and saying "no" based on stock reasons (Izraeli \& Jick, 1986).

Under this management model, divisive gossip, rumors, jokes and stories are viewed as cultural antimatter that can be quite damaging. A great deal of time and effort has often been devoted to integrating the workforce, fostering a positive public image and producing as high a level of performance as possible. Alternative norms and values as well as competing forms of communication therefore tend to be perceived by managers as evils (Danziger, 1988; Greengard, 2001; Burke \& Wise, 2003). Accordingly, virtually any counteracting measure seems well justified.

The rival normal cultural matter view also has a long history. 
Human Relations field research discovered employees typically reacted to the prevailing formal organization by forming their own informal organization (Roethlisberger \& Dickson, 1939). In the early 1900s, managers generally thought of employees as isolated individuals. One can better understand work situations if the groups that have formed are recognized. Frustrated employees tend to share their feelings with one another. Shared sentiments (i.e. group norms) were discovered, which often stood in opposition to formal controls. These included one should not work too fast and one should not tattle.

Due to the oppositional nature of many of the norms and activities associated with informal organization, many managers would like to destroy it. Roethlisberger (1945) argued this would be a mistake. Many basic human needs are provided for by the employees' informal organization. Boring routine jobs can be made more tolerable via the workers' jokes, storytelling, nicknaming, game playing and other forms of socialization (Walker \& Guest, 1952; Roy, 1960; Burawoy, 1979; Fortado, 1998; Gabriel, 2000). Bonding together via these social processes provided employees with emotional support, greater status and some degree of shared power.

Group boundaries can be identified in no small part by examining patterns in gossiping (Gluckman, 1963). Employees naturally take an interest in the people and events that surround them. One can hardly be a member of a group without sharing what has recently occurred and placing it in a historical perspective. Rank has its privileges, but everyone can engage in informal communications. The weak can share their thoughts with friends. This helps them cope with their disadvantaged situation. Sometimes surface harmony will be maintained, while hostilities are dealt with behind the scenes.

Employees often tell stories that show what the managers and the organization are like (Fortado, 1992, 1998; Gabriel, 1995, 2000). Some of what is said is humorous or entertaining. There is also a serious side. These remarks both reveal and reinforce what people do and do not approve of (March \& Sevon, 1984). When differences in interests exist and inequities are perceived, employees have proven to be very creative in finding ways to resist (LaNuez \& Jermier, 1994; Ackeroyd \& Thompson, 1999; Fortado, 2001).

Experience has shown when managers try to exert greater control, the results can be paradoxical (Gouldner, 1954a; Martin, 2002). Gouldner (1954b) has described a case situation where a new leader implemented a crackdown. New regulations were enacted. This resulted in some greater compliance along with some new resistance. Both of these outcomes encouraged the addition of more regulations. The workers progressively became more rebellious. In the end, the effort to exert greater control resulted in control slipping away. This scenario has been called "the paradox of control."

Under this interpretive or interactionist model (Blumer, 1969), all forms of informal communication are viewed as normal cultural matter. Since power does not exclusively reside with the managers, aspects of the existing social realities have been negotiated (Knights \& McCabe, 2003). Some have argued that these subjective areas constitute a terrain that is not and cannot be managed (Gabriel, 1995). Others believe informal organization can be influenced, but not totally controlled (Moore, 1988).

\section{Gathering Case Material}

Our inductive analysis will be grounded on case examples that were gathered in the USA (Glaser \& Strauss, 1967). Field interviews, like the ones relied upon here, were started in 2006 as a part of a larger organization culture project. No consulting relationship, past or present, existed with any of the organizations involved in this research. All of the actual names of the organizations and people have been disguised.

Well known interviewing methods were used (Rogers \& Farson 1988; Whyte, 1984; Roethlisberger \& Dickson, 1939). The interview guide contained a mixture of specific background questions and open-ended cultural questions. An Institutional Review Board reviewed and approved this guide.

The background questions were covered first, so participants could relax and become comfortable with being interviewed (Appendix). They were subsequently encouraged to talk at length about the cultural subjects that were of interest to them. The participants were not interrupted. The interviewer did not morally judge anything that was said. Virtually all of the ensuing examples of informal communication were obtained by asking about other subjects. Some of the most useful questions were asking what big changes had taken place and what events had produced a strong emotional reaction.

The interviews were recorded. This is the most highly recommended way to lessen interpretive errors (Mishler, 1986). Company documents and websites were examined. This process added as well as verified information. Involving an insider is another way to improve the accuracy of field reports (Fortado, 1990). After a draft of our findings was prepared, certain matters were clarified via participant consultation.

\section{The Value Stores Case}

Tim Barr had worked for the Value Stores retail chain for about two years. The company had roughly 1,500 stores and 300,000 employees. A store would typically have 150 to 225 employees. Initially, John Smith was Tim's store manager. There were also eight department managers. Below this, there were a series of team leaders. Tim currently worked in the receiving and reverse logistics area.

Tim viewed five hours of DVDs during his orientation. He was told about the chain and its culture. Tim remembered the catchy slogan the company employed. However, he normally did not think about this slogan as he carried out his job. Other cultural material was also conveyed. The new employees were told to be as one in a team environment, and accept and respect other people. These values seemed like common sense to Tim, so he did not pay much attention to them. He knew that the mission and vision statements were posted in the break room. Tim normally just walked by them.

Tim mentioned the daily meetings. Great team player award cards were regularly presented to encourage good behaviors. These cards were posted on a wall. At the end of the month, a drawing was held from these cards. The winners received $\$ 10-20$. Tim personally was not motivated by these cards. He thought his friends felt much the same way. Most of them were given to people from the sales floor. These awards did not seem like a big deal, because they were given out every day. Nevertheless, Tim put a lot of effort into his job. He took pride in what he was doing.

Tim had friends who worked at the store in various departments. It was these friends who persuaded him to apply for a job. After Tim was hired, they still continued to socialize outside of work. Over time, this group became closer. The main topic of conversation in the upcoming days was interesting events that happened at work. Tim found most of the informa- 
tion he obtained via the grapevine to be accurate.

John Smith held a party one evening at his residence. Many of the managers from his store attended. Mary Mooney, the manager of the back of the store, was left in charge that evening. Various versions of what took place at the party circulated among the employees. The simplest version was that after consuming alcohol, some of the female department managers took off their clothes. Photos of them were taken.

In the days that followed, Mary Mooney saw the pictures. She e-mailed the district manager. The district manager then confronted John Smith. This resulted in him quitting. The rest of the managers who attended the party were transferred over time. The group involved was thereby completely broken up. Mary Mooney also moved to a store in an area where she came from. This meant the store had entirely new leadership.

Tim first heard about this scandal from Terri Small, his team leader. Terri was a friend of one of the female managers who had allegedly taken her clothes off.

At one of the daily area meetings, Mary Mooney instructed her subordinates not to talk about why John Smith left or they would be in trouble. This instruction was not obeyed. New details emerged as Tim heard different accounts of the evening. In one, it was claimed there were drugs involved. In another, it was claimed certain people had sex. The most extreme version asserted the party had turned into a big orgy. As Tim heard one version after another, he found himself wondering what really did happen.

Earlier in his interview, Tim explained that he respected John Smith. Yet, he seemed cold and distant like "Robocop." This sounded like a wild college party to Tim and his friends. Thus, this gossip humanized the managers and made them less distant.

Tim explained Mary Mooney was not well liked. She came from another company. Tim felt that she acted "all high and mighty." He called her a "micromanager." She would check on her subordinates 24/7 (i.e. 24 hours a day, seven days a week). Tim said at times Mary would check on things every five minutes.

When Tim moved to the back of the store, his team leader, Terri, taught him his new job for a few weeks. Terri showed him how to do certain things. She did other tasks entirely herself. Tim learned to do reverse logistics. Terri took care of receiving. This was in keeping with the formal job descriptions.

It was discovered that Terri was dating a manager who also worked in this store. There was a company policy that prohibited a manager from having a relationship with a team member in the same location. The manager chose to move to another store. They eventually married. Terri's team leader position was eliminated for this section. There would still be a team leader for the back of the store, but not for the loading area. Terri told Tim that she might be moving to another team leader position within the store. After this, he was told she might be taking a team leader position in another store. This did not in fact happen. Terri decided to quit. She felt "tugged around" and took it personally.

At this point, Tim was expected to take over all of the duties in the area. He only knew how to do reverse logistics. There was no one else in this store to ask questions about receiving. He felt a great deal of pressure from Mary Mooney to get all of the work done. She kept checking on his progress. After experiencing about a month of great frustration, Tim finally mastered the receiving tasks.

One of the main ways Tim learned to do these new duties was by developing informal relationships with receiving people from other stores. He also found a company website that contained a great deal of useful information. This combination of formal and informal communication channels eventually overcame the problem.

A new coworker, Darcy Mann, later joined Tim. At this point, he believed that he knew even more than Terri had. He treated Darcy like a partner. He informally cross trained her in both receiving and reverse logistics. Formally, one was a specialist in receiving and the other in reverse logistics. Day-to-day, they worked together on aspects of the job as a team, rather than segmenting the tasks according to the job descriptions. Arguably, what was informally done here was far better for the organization. It made the day-to-day work easier, and left the operation less vulnerable if one of the two left.

\section{The Insuro Case}

Insuro was a health insurance company with roughly 7,400 employees. The company had a strong credit rating. It had produced positive financial results each year for over 15 years. Insuro had a thirty percent market share within the region it served. This was more than double its nearest competitor. The leadership was committed to the communities Insuro operated in. In 2006, the company had given over 19 million dollars in charitable contributions. Its employees also did 30,000 hours in volunteer work.

According to the management, organization culture was part of the company's DNA. The mission, vision and values were covered in the employee orientation. There were catchy slogans aimed at both customers and employees. One of the central themes was providing better customer service than its competitors did. Continuous improvement was another one of the company's values. For more than a decade, Insuro had been trying to reduce its costs. A study had revealed the organization's administrative costs were among the highest of providers doing the same type of work. A variety of methods were used to get administrative costs down. The primary way was by reducing staff.

During the 1990s, the organization had flattened itself and adopted a team design on the lowest levels. Many middle level management positions were eliminated. The gap between first line managers and the director level was very large. This made it more difficult for managers to be promoted. Over time, it was decided too much power had been delegated downward. Performance had slipped. Some of the old formal controls were reasserted. This involved monitoring additional calls, enacting progressive discipline and being more demanding in performance evaluations.

In 2002, voluntary severance packages were offered to reduce costs. In subsequent years, some divisions and departments carried out reorganizations that resulted in layoffs. Between 2006 and 2008, 1100 jobs were cut. This was about 13\% of the workforce. Roughly 100 claims processing jobs had been outsourced to a third world country. This move was not publiccized. Those who knew of this change had either learned of it via their work assignment or the grapevine.

Annual surveys revealed increased stress existed. Employees feared they might lose their jobs. Those who remained were also pushed to do more work.

On occasion, quite different stories were put forward about aspects of the historic reorganizations. One example of this was when a team was moved to the supervision of a new director. The formally stated reason for the move was this would be a better fit. Informally, the reason given was that this director 
needed five more people in order to maintain his title. In another case, a manager had made a female employee cry on numerous occasions. Instead of stating that she was being moved due to this supervisory problem, it was said there was a better strategic fit elsewhere. In such instances, many employees believed the gossip about what was taking place more than the formal line.

Insuro used both Six Sigma project teams and Rapid Process Improvement teams. The proposed improvements generated fell into three basic categories: namely, trying to help obtain new business, cut out unnecessary bureaucracy, and reduce costs.

Some of the changes made were not entirely well received. For example, Marcia mentioned all desktop printers being eliminated to cut costs. Now she had to walk to a central laser printer to pick up her documents. Marcia doubted this saved much money and felt the process had gone too far.

At the same time other steps were taken. Recycled toner cartridges were adopted. The darkness of the print was adjusted downward, so only draft quality documents were produced. Complaints soon were made about documents being too light to be useful. Frequent printer adjustments were now necessary. Only one print cartridge could be ordered at a time. Recycled toner cartridges did not last as long. Having no inventory on hand quickly became a source of irritation. The explanation for this practice was holding an inventory could be wasteful. If a printer broke and it could not be economically repaired, there might not be an alternative use for the remaining cartridges.

Some employees argued against having their desktop printers removed due to the fact they needed to print confidential documents. This argument was overcome by having security codes placed in the central printer. These codes restricted access to the documents. Some employees, though, had difficulty remembering the codes.

Originally, Insuro provided better pay and benefits than its competitors. Over time, the drive to reduce costs meant the objective became to provide average levels of compensation. Employees from certain areas reported their raises were unaffected. Others said reductions had been made. Some employees grumbled to one another about why one should be a "best performer" if one got the same raise or a very little additional raise. The average raise in this area at the time was $3 \%$.

The amount of paid time off awarded per paycheck was uniformly cut by roughly 30\%. This produced markedly lower morale on employee surveys. While the cuts were not reversed, other changes based on employee suggestions were made to cheer the employees up. For instance, they were allowed to wear more casual dress. Free coffee, tea and hot chocolate were given. A car wash was also provided.

In 2006, sales were increased by stressing PPO rather than HMO products. PPO products cost less. The new lower administrative costs helped Insuro achieve this success. Ironically, the past staffing cuts resulted in an insufficient number of customer service representatives being available to deal with the new volume of business. This translated into slower phone response times. The employees realized this would impact their appraisals and raises. Since this situation was beyond their control, it seemed unfair.

A cultural item would be given out each year to show appreciation and foster a sense of company pride. Historically, the employees had been given an Insuro picnic blanket, lawn chair, and umbrella. Various smaller cultural items were also produced and distributed. If one got a complimentary letter from a customer, a star shaped Insuro slinky might be awarded. Alternatively, when something had been done well the employee would be allowed to choose an item from a big box of toys. This box included among other things fluffy men, fluffy toys, Star Wars figures, and laptop bags.

Some areas had adopted their own higher level forms of cultural recognition. In one department, every six months a committee would select a small number of award winners. One could be nominated by a manager or a coworker. The winners might be given a recognition lunch, a \$500 reward, a name engraved crystal star award, and a name inscription on a hall of stars plaque. Another form of recognition involved taking award winners on a dinner cruise to a city 30 minutes away.

Some employees told their peers that they would have been happier if they were given the money involved in producing the smaller cultural items (i.e. \$2-\$14). One said the toys should have been cut to save administrative costs. Overall, some of the items, like the umbrella, were seen as much more useful than others, like the lawn chair.

In one meeting, an employee asked why the company was spending money on these cultural items and then saying there was no money to send people in her area to training classes. A manager assured her that an effort would be made to find money for important training classes. Feelings along these lines also surfaced elsewhere. For example, Jan felt that it was wrong for the company to be spending money on these cultural items when so many cost cuts and layoffs were being made. Evidently, the very items that were meant to improve company identification, spirit and morale were having the reverse impact for some employees. The feelings were often shared with coworkers.

High level officers like VPs and directors would periodically meet with a group of 15 employees for lunch. Recently, a HR manager also attended. The formal remarks regarding what was happening at the company and how they were performing consumed most of the time. Only a few minutes were left for questions. One employee asked with all the cuts that had been implemented, why were so many people being promoted to new VP positions? The HR manager responded that this was their natural progression and they now qualified for that job. This was not deemed to be an acceptable answer by some of the employees present, but the issue was not pursued. One attendee later said the positions were simply created for these individuals and they applied for them.

In general, employees were reluctant to get on the bad side of managers from the highest levels. History had shown this could be "career limiting." Some of those who had complained about managers or raises in the past had been targeted in one of the reorganizations. Whereas employees might lose their jobs, managers normally received lesser treatment. For example, a manager might be moved from supervising a team of 13 to 15 to a team of one or two. Disagreeable managers might get labeled by a superior. If those above agreed, the person would probably never be able to shake it.

These perceived inconsistencies and inequities produced more than just internal gossip. When Insuro was getting news coverage for its donations to a major community activity in 2005, someone leaked news to the press about upcoming layoffs. This drew attention to the large amount of money being spent on public giving, while at the same time job cuts were being made. Many of the impacted employees first heard of the upcoming layoffs from the press. In another instance, the CEO's salary and multimillion dollar bonus were leaked to the press shortly before some layoffs were to take place. These articles generated even more gossip about these matters.

One corrective action was taken in response. Members of the 
press normally contacted Insuro's media representatives before an article was run to get the official stance on the subject. Internal communication was sped up, so people did not get first notice of employment decisions, such as layoffs, from the press.

Gloria shared the following story. A weight loss contest was started by a group of employees. Gloria had previously won $\$ 25$ in such a contest. Although the amount of money was small, she was proud to have won this competition.

An anonymous report regarding the latest weight loss contest was made to the "Stay on Track" ethics program. Someone would soon be sent to investigate the allegation. As a policy matter, betting pools were officially condemned.

Marcia had expressed some concern about this Stay on Track process earlier. She felt that it was assumed the anonymous charges were true. Next, the employees concerned were closely observed. This could be somewhat intimidating. Marcia thought this was something short of due process. The accused never got to face his/her accuser. Further, the employees involved were not assumed innocent until proven guilty.

In the specific case of the weight loss pool, the group received an informal warning from a VP, Kay. She told all of the participants the contest had been reported to the Stay on Track program. Kay was one of the contestants. Gloria laughed and explained nothing had been put in writing, so nothing could be proven.

In this case, the grapevine provided forewarning. This made it highly unlikely the upcoming investigation would uncover anything. Notably, the contest's outcome would have been based on hard work and discipline, rather than chance or the outcome of a sporting event. Ironically, this weight loss contest would have contributed more to the employees' health than some of the other approved company practices. For example, fried chicken was being served in the cafeteria. To show appreciation and foster greater motivation, free meals were occasionally provided. Overeating could easily result.

Insuro’s workforce was 65 - 70 percent female. The management took pride in pointing out the company had been rated as one of the top ten places for women and minorities to work. Many of the women worked at computer terminals, handling phone calls for much of the day from various customers and medical facilities. At the highest levels, the number of men outnumbered the women.

Our interviews revealed the upper levels were thought to be an "ole boy network." The company had started this way and it was still perceived to largely be this way. Some women did reach the director and VP level. Despite this, Gloria noted that they did not seem to stay in those jobs very long. Erin had served on a diversity counsel. During this time, she asked for breakdown of the number of men and women by level. This information was never provided.

The women who wanted to progress were essentially given no specific practical guidance from the formal company line that Insuro embraced diversity. Instead, ambitious women had to learn what to do and not do via the grapevine.

Robin explained the company encouraged people to earn university degrees. However, she believed the culture placed more value on work experience. Job posting was used rather than managerial nomination. Nonetheless, Robin believed some jobs were far more open than others. According to the gossip, the qualifications for some jobs were manipulated prior to being posted, so only the person the managers had in mind would be a good fit. The best of the rest who applied would get an interview, but no subsequent feedback was typically provided. One had to learn how to fend for oneself.
Erin had started working in an area that dealt with doctors and medical facilities. When she began looking at a promotion opportunity in the area that dealt with patients, her colleagues gave her some words of warning. The majority of the employees there were young women who dealt with policy holders over the phone. These jobs had a high turnover rate. Some of the employees were viewed as immature. For all of these reasons, this was considered to be a lower status area. Erin was offered the job and she took it. After spending some time there, it did not seem to be so bad. Her job, though, was not a managerial one dealing with the employees who she had been warned about.

Erin outlined a number of things that she had learned about furthering her career. Who you know was very important. It was critical that one provide deliverables by a known deadline. After proving themselves, women then had to take steps to get acknowledged for that. They had to express an interest in being promoted and build a case for it. Innovation was being valued recently, so you had to present new ideas. At the same time, you had to avoid being perceived as someone who "rocked the boat."

Women could disagree, but it had to be done very professionally. Women who were disrespectful, rude or flew off the handle in meetings would develop a bad reputation. This bad image would stick with them. Women could foresee certain outcomes. Yet, if they did not get their way, they had to accept this gracefully.

Erin recalled a time when her former female manager did not get her way. She concluded the discussion by saying "OK. Whatever, we will do that.” She complied, but her tone was noted. She got labeled as having "a bad attitude" and was unlikely to get promoted. Erin explained whereas men might be admired for being confident or aggressive, women had to beware being perceived as "pushy or bitchy."

Robin also had worked for a female manager who had been labeled as not playing the game. She generally wanted to "put her two cents in.” On numerous occasions she had suggested improvements. The male managers surrounding her would do each other favors. She questioned some of these decisions. The men responded that they all agreed, so she was wrong. This resulted in her being thought of as "a bad influence.” There were a number of common background characteristics that may have contributed to the men's unity. Some of them had served in the Navy together. Some had also worked together at a bank. When the time came to make a promotion decision, men who were well known tended to be promoted. This "ole boy" system was very real to many Insuro women.

Erin had told her current male manager that she hoped to be promoted one day. He stressed the importance of networking. Erin was well aware her manager regularly ate lunch with various people to network. In contrast, she tended to eat by herself. Erin acknowledged she was more introverted than he was. In order to help her meet managers and become better informed, he arranged for her to attend managerial meetings.

This might seem like a small matter, but it was not. The managers typically would not share much information with subordinates. Robin felt they viewed themselves as a different social class. This restricting information norm was evident to employees when they approached managers, because they frequently would suddenly stop talking.

\section{Discussion}

Various forms of informal communication played prominent 
roles in these social situations. The official managerial rhetoric and practices were being either overtly or covertly challenged. When everything did not go entirely as some of the managers would have liked, corrective measures were undertaken. Once again, unintended results ensued.

The managers at Value Stores had a culture program and a fraternization rule. Mary Mooney forbade her team members from talking about why John Smith left. The tales that were told nonetheless multiplied with new titillating details being added over time. Mooney's order was occasionally recounted as a preface to more gossiping. This prohibition paradoxically fueled the very fire it was meant to extinguish (Foster, 2004).

Insuro had both a continuous improvement and culture program. A gossip spiral developed. First, the employees gossiped about the inconsistencies and inequities of their managers' lengthy drive to cut administrative costs. Some Insuro managers gave their employees a chance to ask questions. A number of concerns were raised in meetings. It may have seemed like the managerial explanations were accepted. Some modest course adjustments were made. Nevertheless, discontent continued to mount behind the scenes. People gossiped about their managers reactions. An anonymous source got a newspaper to print several provocative articles. These articles were then gossiped about.

In both cases, the attempts to silence dissent made matters worse. The managers proved to be less than fully forthcoming and responsive. This conveyed a lack of trust and respect. Employees can easily conclude their managers are aloof and do not care much about to them. Disgruntled employees often assert their independence by secretly partaking in more gossip. Doing so can be pleasurable, cathartic and empowering. Our cases suggest there are different manifestations or evolutionary paths. Since the chosen remedial actions failed, a more sophisticated contingency approach is evidently needed.

The effort to exert greater control in both companies paradoxically resulted in control slipping further away. Whether the managers realized this was another matter. Many managers have historically failed to fully see how festering unresolved conflicts tend to undergo a metamorphosis that can greatly undermine their efforts (Fortado, 2001). Just as Human Relations researchers productively critiqued the old efficiency mentality, fieldwork can do much the same with many management practices today.

A popular recommendation to get out of the paradox of control is to delegate power and rely more on self control and peer discipline. Value Stores used the term "team" regularly. Most team members, though, were not actually empowered to make many meaningful decisions. Some of the increased delegation at Insuro was later reined in, because performance had slipped. Tensions were bound to rise as a result.

A recent field study of a hospital found rumors were created by the stress of undergoing a change process (Bordia, et al., 2006). It remains to be seen if popular cultural change efforts will generally lessen divisive informal communication. The limited existing fieldwork conducted by detached researchers suggests such programs may not be a panacea. Salient differences have been found between what some managers say and what they do, work can be intensified, painful budget and staff cuts may be made, hierarchical power relations tend to persist, and when things do not go as planned, traditional controls may be reasserted (Grenier, 1988; Kunda, 1992; Reynolds, 1994; Watson, 1994; McKinlay \& Taylor, 1996; Ezzamel, Willmott \& Worthington, 2001; Knights \& McCabe, 2003; Fleming, 2005). Such matters frequently provide the fuel for destructive gossip, rumors, jokes and stories as well as other forms of resistance.

Dyadic gossip and rumor theory has focused on how verbal messages are passed from a sender to a receiver (Kurland \& Pelled, 2000). The photos and the newspaper articles in our two cases showed gossip can be seen as well as heard. Celebrity tabloids have long used these forms. Moreover, "the receiver" can be plural. A sender may speak in a meeting or to an informal group. Documents are often distributed to large audiences. We also discovered "the sender" may be anonymous. This was the case in the leaks that were made to a newspaper and the report that was made to the "Stay on Track" program. Evidently, our academic taxonomy needs to be inductively expanded.

The scope of gossip, rumors jokes and stories can vary widely. In the Value Stores scenario, the personnel at one store were involved. In contrast, the scope at Insuro spanned all of the internal units as well as the surrounding community. From this point forward, one should consider how broad the scope is internally, ranging from a few people on one end to the entire organization on the other. On the external side, the scope can range from a few members of the local community to very widespread knowledge.

We found value laden statements about both people and things being made behind the scenes. One accordingly could differentiate some items as gossip and others as rumors. When deductive quantitative content analyses are done, mutually exclusive categories are used to produce reliable coding. Should this sort of analysis be done here?

Let us consider two pairs of examples. In the Insuro case, there were two newspaper articles. One reported news about layoffs juxtaposed with the amount of money that had been contributed to a community event. The other reported news about layoffs juxtaposed with the most recent compensation package of the CEO. Frustrations were expressed elsewhere about new expenditures being made on token cultural items. Managers were also asked why so many new VP positions were being created in a meeting. Should we label the former example in each pair a rumor and the latter gossip?

A few caveats should be noted here. Even when the merits of policies and decisions were impersonally discussed, the judgment of the decision makers was being indirectly questioned. Many people talk more directly behind people’s backs. Things tend to be stated less personally in face-to-face interactions or when the subject is likely to hear about it. Many varied degrees of personalization were found in our cases.

Strictly applying the above definitions might confuse rather than clarify matters. Doing so could obscure the common ironic theme that questionable new expenditures were being made during a period of extensive cost cutting. The inconsistencies and inequities the offended employees saw were demonstrated via a series of examples. What people mean should always be our central focus in writing a field research report.

Theoretically thinking solely in terms of one person spreading a particular piece of gossip seems over simplistic. In the Value Stores case, multiple people told various versions of what happened at the party. Situations like this one can crack open the value sets of those involved. Some people enjoy such activities. Others would not do such things, but still find the behaviors to be of interest in terms of their fantasy life or as a source of amusement (Gabriel, 1995). Still others do not approve of what took place, but they are willing to tolerate it. At the other end of the spectrum are those who feel strongly compelled to crack down on the perpetrators. These multiple layers of reactions reflect the diverse or fragmentary elements of an 
organization culture (Martin, 2002).

Some academics have tried to draw a sharp theoretical distinction between positive and negative forms of gossip (Noon \& Delbridge, 1993; Kurland \& Pelled, 2000). In practice, this means one must assume the perspective of a particular person or group. In the Value Stores case, should one take the perspective of the district manager, John Smith, Mary Mooney, or some other person? In the Insuro case, should one take the perspective of the managers who drove the costs cuts, the downsized employees, or some group of the remaining employees? Should one take the perspective of the person who reported the weight loss contest, or that of those in the contest? Should one take the official perspective that Insuro embraced diversity or that of the women who still perceived there to be an "ole boy" network? No perspective is objective or neutral.

What is negative gossip to one person may be truth telling to another. Actions that were labeled as fostering greater integration and stability by some may be seen by others as ignoring their interests and denying them input. What one group views as disruptive dissent can be seen by another as the pursuit of legitimate ends. Praise has historically been categorized as positive gossip. Yet, a competitor could view such remarks as unwarranted spin. One should always consider who is talking and whose voice is left out.

For the moment, let us assume an upper level management perspective. Our fieldwork suggests irritating gossip, rumors, jokes and stories can be found along with other positive aspects of informal organization. At times, what was taking place informally was more productive than some of the formal policies and practices were.

Tim Barr learned how to do his new receiving duties in no small part via informal communication. Subsequently, he crossed trained a new colleague sub rosa. This allowed the two work as a team. It also made the store less vulnerable to turnover. The group of friend's weight loss contest at Insuro was quite likely to produce health benefits. This was more than could be said for the fried chicken that was being served in the cafeteria or the overeating that was likely to result from the free motivational meals. An informal leak effectively put an end to a potentially demoralizing investigation. Some Insuro women listened to the gossip about the good ole boy system and benefited from the grapevine tips on what they could do to get promoted.

One should never remove informal communication from its full and proper social context in theory, research or practice. Managers can easily make evaluative mistakes if they focus on their traditional control measures and formal culture programs, while at the same time they ignore what is informally being said and done. Based on our fieldwork, managers would be ill advised to blindly attack the employees' informal organization. The prevailing human relations could easily become worse instead of better.

Work holds a central place in people's lives. Entire people come to work, not just the portions that can be thought of as biological machinery. Employees are not androids who can be programmed or obedient thralls. They have minds of their own. Subordinates will speak their minds one way or another. When disappointing managerial behaviors generate gossip, rumors, jokes, and stories, the future can still be positively influenced. The question is whether managers are willing to do so, because this may involve painful actions such as admitting mistakes, sharing power and making less money.

The managers in our cases, like many others before them, operated based on the logic of the cultural antimatter view. The cultural matter view, though, provided the best fit with what we found. Instead of thinking in terms one or the other, in practice one really needs to appreciate both views. Doing a proper organization analysis requires an examination of both the formal and informal organization, including where they complement and contradict one another (Dalton, 1959).

Gaps between "what is" and "what should be" often exist (Roethlisberger \& Dickson, 1939). If one accepts that work situations involve managing social exchanges, it logically follows that periodic status assessments should be made. One would start with a field study of the basic beliefs and values of the employees (Moore, 1988: p. 13). The way the social system operated would be described. Next, one could consider how, if at all, the organization could be made more effective. After making a change, some ongoing observation would take place. Adjustments would then be made as needed.

Many managers take a dim view of employee gossip, rumors, jokes and stories, because distortions, exaggerations and omissions can occur. Yet, employees tend to believe most of what they have heard via the grapevine is accurate (Daft \& Steers, 1986: p. 541). This schism needs to be recognized. The reasons for it should also be considered.

Certain people serve as the conduits for the exchange of information up and down the hierarchy (Dalton, 1959). One can share what one knows and learn what one does not know. Employees often learn about what the managers are discussing and what has been decided. Managers frequently learn about what the employees are talking about. Some of the aforementioned schism could be explained by these positional differences.

Prior field research has shown managers sometimes use the grapevine to create useful false impressions (Fortado, 1994). Moreover, when things have not gone well, efforts may be made to pass the blame or cover up (Jackall, 1988). In our cases, some employees found gossip about personal or political motives to be more credible than what the official line was. Given a specific situation, one could ponder whether such conclusions are accurate or merely a conspiracy theory. Long ago, Thomas (1928: p. 572) pointed out what is real to people is by its very nature real in its consequences. Thus, attempting to determine an objective answer appears to be a moot point.

When managers copy a "best practice" or implement a new culture program, they may overlook key aspects of the social situation (Knights \& McCabe, 2003). Informal communications are far from just idle chatter. People act based on their interpretations. Interpretations are founded on historic experiences and the social context (Roethlisberger \& Dickson, 1939; Blumer, 1969). The grapevine shapes employee sentiments about the company and specific people. It would be imprudent to ignore these social facts.

Many managers would greatly benefit if they could learn to do sociological analysis. The relational and emotional components of informal communications can serve as a thermometer that roughly gauges the warmth of human relations. The specifics, while not always completely accurate, can also contribute to ongoing diagnostic processes. Managers periodically need to determine how things got to the current state of affairs and, if need be, what can now be done to improve upon matters.

\section{Acknowledgements}

An earlier version of this paper entitled "Organizational gossip: Cultural matter or antimatter?" was presented at the 24th EGOS Colloquium, Amsterdam, The Netherlands, July 10-12, 2008. The author would like to thank Piers Myers and Grant Michelson for their comments. 


\section{References}

Ackeroyd, S., \& Thompson, P. (1999). Organizational misbehaviour. London: Sage.

Barker, J. R. (1999). The discipline of teamwork: Participation and concertive control. Thousand Oaks, CA: Sage.

Barnard, C. I. (1938). The functions of the executive. Cambridge, MA: Harvard University Press.

Blumer, H. (1969). Symbolic interactionism: Perspective and method. Englewood Cliffs, NJ: Prentice-Hall.

Bordia, P., Jones, E., Gallois, C., Callan, V. J., \& Difonzo, N. (2006). Management are aliens! Rumors and stress during organizational change. Group and Organization Management, 31, 601-621. doi:10.1177/1059601106286880

Burawoy, M. (1979). Manufacturing consent. Chicago: University of Chicago Press.

Burke, L. A. \& Wise, J. M. (2003). The effective care, handling, and pruning of the office grapevine. Business Horizons, 46, 71-76. doi:10.1016/S0007-6813(03)00031-4

Daft, R. L., \& Steers, R. M. (1986). Organizations: A micro/macro approach. Glenview, IL: Scott Foresman.

Dalton, M. (1959). Men who manage. New York: Wiley.

Danziger, E. (1988). Minimize office gossip. Personnel Journal, 67, 38-42.

Ezzamel, M., Willmott, H. \& Worthington, F. (2001). Power, control and resistance in 'The factory time forgot.' Journal of Management Studies, 38, 1053-1079. doi:10.1111/1467-6486.00272

Fleming, P. (2005). 'Kindergarten cop:’ Paternalism and resistance in a high-commitment workplace.” Journal of Management Studies, 42, 1469-1489. doi:10.1111/j.1467-6486.2005.00551.x

Fortado, B. (1990). The responsibilities of a semi-structured interviewer. Employee Responsibilities and Rights Journal, 3, 31-46. doi:10.1007/BF01384762

Fortado, B. (1992). Subordinate views in supervisory conflict situations: Peering into the subcultural chasm. Human Relations, 45, 1141-1167. doi:10.1177/001872679204501102

Fortado, B. (1994). Informal supervisory social control strategies. Journal of Management Studies, 31, 252-274. doi:10.1111/j.1467-6486.1994.tb00774.x

Fortado, B. (1998). Interpreting nicknames: A micropolitical portal. Journal of Management Studies, 35, 13-34. doi:10.1111/1467-6486.00082

Fortado, B. (2001). The metamorphosis of grievance conflict. Human Relations, 54, 1189-1221. doi:10.1177/0018726701549003

Foster, E. K. (2004). Research on gossip: Taxonomy, methods, and future directions. Review of General Psychology, 8, 78-99. doi:10.1037/1089-2680.8.2.78

Gabriel, Y. (1995). The unmanaged organization: Stories, fantasies and subjectivity. Organization Studies, 16, 477-501. doi:10.1177/017084069501600305

Gabriel, Y. (2000). Storytelling in organizations: Facts, fictions, and fantasies. New York, NY: Oxford University Press.

Glaser, B. G., \& Strauss, A. L. (1967). The discovery of grounded theory. Chicago, IL: Adline.

Gluckman, M. (1963). Gossip and scandal. Current Anthropology, 4, 307-316. doi:10.1086/200378

Gouldner, A. W. (1954a). Patterns of industrial bureaucracy. New York: Free Press.

Gouldner, A. W. (1954b). Wildcat strike: A study in worker-management relationships. New York, NY: Harper \& Row.

Greengard, S. (2001). Gossip poisons business: HR can stop it. Workforce, $80,24-28$.

Grenier, G. J. (1988). Inhuman relations. Philadelphia, PA: Temple
University Press.

Izraeli, D. M., \& Jick, T. D. (1986). The middle manager and tactics of power expansion: a case study. Organization Studies, 7, 171-192. doi:10.1177/017084068600700206

Jackall, R. (1988). Moral mazes: The world of corporate managers. Oxford: Oxford University Press.

Jacoby, S. M. (1985). Employing bureaucracy. New York, NY: Columbia University Press.

Knights, D. \& McCabe, D. (2003). Organization and innovation: Guru schemes and American dreams. Berkshire, England: Open University Press.

Kunda, G. (1992). Engineering culture: Control and commitment in a high-tech corporation. Philadelphia, PA: Temple University Press.

Kurland, N. B., \& Pelled, L. H. (2000). Passing the word: Toward a model of gossip and power in the workplace. Academy of Management Review, 25, 428-438.

LaNuez, D., \& Jermier, J. M. (1994). Sabotage by managers and technocrats: Neglected patterns of resistance at work. In J. M. Jermier, D. Knights, \& W. R. Nord (Eds.), Resistance and power in organizations (pp. 219-251). London: Routledge.

March, J. G., \& Sevon, G. (1984). Gossip, information and decision-making. Advances in Information Processing in Organizations, 1, 95-107.

Martin, J. (2002). Organization culture: Mapping the terrain. Thousand Oaks, CA: Sage.

McKinlay, A. \& Taylor, P. (1996). Power, surveillance, and resistance: Inside the "factory of the future." In P. Ackers, C. Smith, \& P. Smith (Eds.), The new workplace and trade unionism (pp. 279-300). London: Routledge.

Mishler, E. G. (1986). Research interviewing: Context and narrative. Cambridge, MA: Harvard University Press.

Moch, M., \& Huff, A. S. (1983). Power enactment through ritual and language. Journal of Business Research, 11, 293-316. doi:10.1016/0148-2963(83)90014-0

Moore, D. G. (1988). Industrial anthropology: Conditions of revival. City \& Society, 2, 5-18. doi:10.1525/city.1988.2.1.5

Morgan, G. (2006). Images of organization. Thousand Oaks, CA: Sage.

Noon, M., \& Delbridge, R. (1993). News from behind my hand: Gossip in organizations. Organization Studies, 14, 23-26. doi:10.1177/017084069301400103

O’Day, R. (1974). Intimidation rituals: Reactions to reform. Journal of Applied Behavioral Science, 10, 373-386. doi:10.1177/002188637401000310

Reynolds, P. C. (1994). Corporate culture on the rocks. In T. Hamada and W. E. Sibley (Eds.), Anthropological perspectives on organizational culture (pp. 301-310). Lanham, MD: University Press of America.

Roethlisberger, F. J. (1945). The foreman: Master and victim of doubletalk. Harvard Business Review, 23, 285-294.

Roethlisberger, F. J., \& Dickson, W. J. (1939). Management and the worker. Cambridge, MA: Harvard University Press.

Rogers, C. R., \& Farson, R. E. (1988). Active listening. In P. B. Dubose (Ed.), Readings in management (pp. 184-95). Englewood Cliffs, NJ: Prentice-Hall.

Roy, D. F. (1960). “Banana time:” Job satisfaction and informal interaction. Human Organization, 18, 158-168.

Thomas, W. I. (1928). The child in America: Behavior problems and programs. New York: Knopf.

Walker, C. R., \& Guest, R. H. (1952). The man on the assembly line. Cambridge, MA: Harvard University Press.

Watson, T. J. (1994). In search of management. London and New York: Routledge.

Whyte, W. F. (1984). Learning from the field. Beverly Hills: Sage. 


\section{Appendix. Interview Guide}

What does "organization culture" mean to you? Where have you heard of this term? How does your organization define it? Have you seen it defined at school? Have you seen any other definitions? What are your thoughts on organization culture?

What is your job title? Who do you work for? What other jobs have you held?

When does your workday start? Do you have any breaks? When are you done? Do you have any goals or targets? What are they? How are you paid? Are there different shifts? Do you have to work any overtime? How are overtime assignments made?

How did you learn how to do your job? Tell me about what you do. Are there many rules and procedures? Do people ever cut corners? Are there any methods that you use which are not formally taught? Could you give me some examples? Is it pretty clear what you should and should not do? Could you give me some examples? Are workers watched pretty closely, or are they largely left on their own to get the job done?

Who is your boss? How much do you see or hear from your boss every day? What is your boss like? Could you give me some examples that show what he is like? When someone is not doing the right thing, how does your boss handle the situation? Could you give me some examples?

How many people are in your group? How much do you see or hear from coworkers? What are your coworkers like? Could you give me some examples of what they are like? When someone is not doing the right thing, how do your coworkers handle the situation? Could you give me some examples?

Who are the managers above your boss? How often do you hear or see them? What are they like? Could you give me some examples that show what they are like? When someone is not doing the right thing, how do these managers handle the situation? Could you give me some examples?

What type of decisions do you make at work? What type of decisions does your boss make? What type of decisions does his/her superior make? Is it clear who should do what? Are the people who make the decisions also held accountable for the decisions?

Have you seen any big changes over time? Have you moved to a new organization? Have you changed jobs? Has there been a merger? Has there been a leadership change? Has there been structural change, such as shifting to a team design? Tell me about these changes? What were things like at first? How did things change?

Can you think of any events that produced strong emotional reactions? Could you tell me more about that? What were the emotions? What happened?
How do you learn about things at work? (e.g. meetings; memos; e-mails; the boss; the grapevine, meaning coworkers or other workers; or other means) Are you kept well informed? Do you understand how decisions are made? Have there been any sudden changes? Tell me about that change. Are your questions promptly answered? Were the answers clear? Could you give me some examples? Have there been any rumors? Could you give me some examples? Do you normally hear about what is going to happen before it is formally announced? Could you give me any examples?

How often do you have meetings? Who do you meet with? What are the meetings like?

Does the organization have any ceremonies and rituals? (e.g. a retirement ceremony, merit awards, service awards, the introduction of a new boss, a promotion ceremony)

Do people ever tell you stories? Could you give me some examples?

Do you know much about the history of the organization? What things stand out in your mind? How did you learn about these things?

Do you have any printed shared values, slogans, or mission/vision statements? Does the organization distribute any items with company logos or slogans on them? What do you think about these items?

Has your company had any leaders that stand out? Tell me about them.

Do your coworkers have any norms, meaning unwritten codes of conduct, regarding how people should and should not act? Could you give me some examples? (e.g. do not tattle, do not brown nose, do not work too fast, do not act too big) How are these conveyed to newcomers? What happens if a worker does not want to go along? (peer pressure, verbal requests, looks, comments, teasing, nicknaming, ostracism, binging, etc.)

How are people rewarded for good performance? (high performance appraisals, raises, promotions, bonuses, other merit recognitions, being able to bend the rules, running up an expense account, cutting corners on time, etc.)

Do people tell jokes about things that have happened at work? Could you give me any examples?

Are any nicknames used at work? Could you give me some examples? Where did that come from? What is that person like? Could you give me some examples?

What is currently going well at work? What could be improved? What is the best thing that has happened at work? What is the worst thing that has happened?

What is the reality of your work situation with respect to the following subjects: namely, 1) job security, 2) recognition, 3) equity, 4) trust, and 5) respect? What made you say that? You could explain what led you to that conclusion? 